\title{
NF-E2-related factor 2 serves a key function in resistance to malignant transformation of BEAS-2B cells induced by coal tar pitch
}

\author{
SONGCHENG YU ${ }^{1}$, ZHEN YAN $^{1}$, FEIFEI FENG $^{1}$, JING NI $^{1}$, WEI WANG $^{1}$, KADIJATU NABIE $^{1}$, \\ YIGUO ZHANG $^{2}$, LINGBO QU $^{3}$ and YONGJUN WU ${ }^{1}$ \\ ${ }^{1}$ College of Public Health, Zhengzhou University, Zhengzhou, Henan 450001; \\ ${ }^{2}$ College of Medical Bioengineering and Faculty of Life Sciences, University of Chongqing, Chongqing 400044; \\ ${ }^{3}$ College of Chemistry and Molecular Engineering, Zhengzhou University, Zhengzhou, Henan 450001, P.R. China
}

Received August 2, 2016; Accepted November 29, 2017

DOI: $10.3892 / \mathrm{ol} .2018 .7924$

\begin{abstract}
Coal tar pitch (CTP) is a key factor in the development of occupational lung cancer. In order to investigate the function of the anti-oxidative signaling pathway regulated by NF-E2-related factor 2 (Nrf2) during cancer development, BEAS-2B cells were cultured with CTP extract for 30 passages. It was revealed that malignant transformation occurred in cells between the 20 and 30th passage. The expression levels of Nrf2 and NAD(P)H:quinone oxidoreductase 1 (NQO1) were promoted throughout the CTP exposure culture, and there was a positive linear correlation between the expression levels of Nrf2 and NQO1. Following knockdown of Nrf2 expression, the level of NQO1 decreased markedly and malignant transformation was more likely to occur. It was hypothesized that CTP may be toxic to BEAS-2B cells, which may lead to malignant transformation. Nrf2 was a quick response factor: Counteracting cytotoxicity by promoting the expression of anti-oxidative genes. Thus, Nrf2 was associated with the malignant transformation of BEAS-2B cells exposed to CTP and may be a potential therapeutic target.
\end{abstract}

\section{Introduction}

Coal tar pitch (CTP) has been determined to be a potent risk factor to human health. This material represents the collective

Correspondence to: Professor Yongjun Wu, College of Public Health, Zhengzhou University, 100 Kexue Avenue, Zhengzhou, Henan 450001, P.R. China

E-mail:wuyongjun@zzu.edu.cn

Abbreviations: ARE, antioxidant response element; CTP, coal tar pitch; DMSO, dimethyl sulfoxide; NQO1, NAD(P)H:quinone oxidoreductase 1; Nrf2, NF-E2-related factor 2; PAHs, polycyclic aromatic hydrocarbons; RNAi, RNA interference

Key words: NF-E2-related factor 2, NAD(P)H:quinone oxidoreductase 1 , coal tar pitch, malignant transformation, RNA interference by-products of the combustion of organic materials that are widely used in everyday life (1-3). Epidemiological studies and animal experiments have demonstrated that CTP is carcinogenic and leads to the development of lung cancer, often considered to be an occupational tumor (4-6). Exposure to aerosols and dust from CTP is toxic to the human respiratory, gastrointestinal and urinary tracts, as well as the skin $(7,8)$. Thus, although CTP serves multiple functions in modern life, its carcinogenicity has attracted attention.

Oxidative damage is one factor that contributes to the development of cancer, by leading to mutations in DNA, including point mutations, deletions, insertions, chromosomal translocations, crosslinks and other modifications (9). Direct DNA damage or genomic instability coupled with altered gene expression and alterations in protein conformation occur simultaneously in cancer development $(10,11)$. The anti-oxidative signaling pathway regulated by NF-E2-related factor 2 (Nrf2) serves an important function in resisting the oxidative damage of external stimuli (12). The antioxidant response element (ARE) is an upstream sequence that regulates the expression of the enzymes that provide resistance to toxins or oxidative stress (13). Nrf2 is a factor required for binding to ARE, along with other nuclear factors, in order to initiate the transcription of downstream genes, including NAD $(\mathrm{P}) \mathrm{H}$ :Quinone oxidoreductase 1 (NQO1) $(14,15)$. NQO1 functions as an important enzyme for protection against the reactive forms of oxygen and inhibition of neoplasia via a number of functions: i) Catalytic activity toward quinones, which are toxic to cells; ii) maintenance of the reduced and active forms of the endogenous lipid-soluble antioxidants, $\alpha$-tocopherol-hydroquinone and ubiquinol; iii) requirement for the stabilization of P53 $(16,17)$.

Therefore, it is important to understand whether the anti-oxidative signaling pathway regulated by Nrf2 serves a function in resistance to the adverse impact induced by CTP. In order to investigate its function in cells exposed to CTP, immortalized human bronchial epithelial cells (BEAS-2B cells) were cultured with CTP extract, and the expression of Nrf2 was knocked down. Subsequently, malignant transformation of BEAS-2B and the expression of Nrf2 and NQO1 at the mRNA and protein levels were monitored. The results 
indicated that Nrf2 was a quick response factor to CTP exposure and was associated with the malignant transformation. The present study shed some light on carcinogenic mechanism and cancer prevention.

\section{Materials and methods}

Preparation of the CTP extract. Raw CTP powder (Henan Branch China Aluminum Co., Ltd., Zhengzhou, China) was heated to $400^{\circ} \mathrm{C}$, and the volatile gas was collected for $100 \mathrm{~min}$ with a common sampling-head. The collected CTP gas was dissolved in $50 \mathrm{ml}$ ethyl acetate, agitated for $10 \mathrm{~min}$ with ultrasonication and filtered with a sand core funnel to remove the debris. Subsequently, the extracts were collected and dried at $45^{\circ} \mathrm{C}$, with the residue then dissolved in dimethyl sulfoxide (DMSO) to a concentration of $2 \mathrm{mg} / \mathrm{ml}$.

Cell culture and survival within CTP. BEAS-2B cells, provided by Professor Weidong Wu (Zhengzhou University, Zhengzhou, China) were maintained in RPMI-1640 (Beijing Solarbio Science and Technology Co., Ltd., Beijing, China) supplemented with $10 \%$ fetal bovine serum (Hangzhou Sijiqing Biological Engineering Materials Co., Ltd., Hangzhou, China). The cells $\left(1 \times 10^{6}\right)$ were cultured at $37^{\circ} \mathrm{C}$ overnight in a 6 -well plate and then co-cultured for $24 \mathrm{~h}$ at $37^{\circ} \mathrm{C}$ with CTP at the indicated concentrations $(1,2.5,5,10,20,40$ and $80 \mu \mathrm{g} / \mathrm{ml})$ along with a blank control, a $5 \mu \mathrm{g} / \mathrm{ml}$ benzo(a)pyrene [B(a)P]-treated positive control and a DMSO vehicle control. Each exposure condition was performed in triplicate. Subsequently, the cells were detached using trypsin, suspended at 2,000 cells/ml and incubated with $0.4 \%$ trypan blue solution $(\mathrm{v} / \mathrm{v}=1: 1)$ at room temperature for $3 \mathrm{~min}$. The cells were evaluated using inverted microscope (cat no. IX71; Olympus, Corporation, Tokyo, Japan) with which the blue-stained and unstained cells were counted at magnification, $\mathrm{x} 100$. The half-inhibitory concentration $\left(\mathrm{IC}_{50}\right)$ of CTP for these cells was calculated using the Probit regression model.

RNA interference for Nrf2 expression. An oligonucleotide encoding short hairpin (sh)RNA targeting the exon region of Nrf2 (177233320-17723340 in chromosome 2, GRCh38.p7) (18) was designed and synthesized according to the nucleotide sequence of human Nrf2. Its nucleotide sequence, as well as those of the negative and positive control [sh-negative control (shNC) and shGAPDH, respectively], are listed in Table I. These sequences were inserted into the U6/green fluorescent protein (GFP)/Neo plasmid (Shanghai GenePharma Co., Ltd., Shanghai, China), and transfections were carried out using $40 \mu \mathrm{l}$ RNAi-Mate Transfection reagent (Shanghai GenePharma Co., Ltd.), according to the manufacturer's protocol. A total of $48 \mathrm{~h}$ later, stable cell lines were screened by administration of G418 (Invitrogen; Thermo Fisher Scientific, Inc., Waltham, MA, USA).

Soft agar assay for colony formation and tumor-bearing mouse model. A cell suspension was prepared by digesting cells with $0.3 \%$ trypsin solution and diluting with culture medium (RPMI-1640 medium supplemented with $20 \%$ fetal bovine serum) to a concentration of $1 \times 10^{6}$ cells $/ \mathrm{ml}$. Cell suspensions were mixed with a penicillin and streptomycin-containing $0.6 \%$ agarose solution at a ratio of $1: 1(\mathrm{v} / \mathrm{v})$. The mixture was then added to 6 -well microplates containing solidified $0.6 \%$ agarose gel with $100 \mathrm{U} / \mathrm{ml}$ penicillin and $0.1 \mathrm{mg} / \mathrm{ml}$ streptomycin. Once the agarose gel had solidified at room temperature, $2 \mathrm{ml}$ culture medium was added. Subsequently, the cells were incubated at $37^{\circ} \mathrm{C}$ in $5 \% \mathrm{CO}_{2}$ for 2 weeks. Aggregates consisting of $>50$ cells were counted as colonies by observation using an inverted microscope (IX71, Olympus, Japan) at magnification, x100.

Subsequently, cells from the blank control, vehicle DMSO control and CTP groups at the 20 and 30th passages were transferred via an intradermal injection to the back of the necks of 18 male BALB/C mice (4 weeks old; average weight $\sim 15 \mathrm{~g}$ ). Mice were free of specific pathogens and had been purchased from Hunan Slack King Laboratory Animal Co., Ltd. (Changsha, China). All the mice lived in the environment free of specific pathogens $\left(25^{\circ} \mathrm{C} ; 50-70 \%\right.$ humidity) with a $12 \mathrm{~h}$ light/dark cycle and were fed a standard full-nutrient diet for medical experimental animals in China (19). The mice were treated humanely and with regard for alleviation of suffering; clean water, sufficient food and sufficient and comfortable room for rest were provided; mice were also housed with companions. The growth of the cells was observed and the tumors, if any developed, were excised for further examination after 30 days. The tumor volume was calculated by the following equation: $\mathrm{V}=($ long diameter $\mathrm{x}$ short diameter $\mathrm{x}$ short diameter $) / 2$.

All animal experiments were performed in accordance with international guidelines for the care and use of laboratory animals, as well as local and national regulations. The mice were sacrificed by inhaling ether 30 days following intradermal injection. The humane endpoint was defined when the tumor reached $1,500 \mathrm{~mm}^{3}$. If the tumor reached this volume, the mouse would be sacrificed ahead of time to relieve pain via inhalation of ether only, even if the experiment was incomplete. However, no mouse was sacrificed in advance due to such large tumor volume during the experiment. The lab in which the animal experiments were performed was certified by the Science and Technology Department of Henan Province (Henan, China; SYXK2012-007). The experimental protocol was approved by the Life Sciences Institutional Review Board of Zhengzhou University (Henan, China).

Reverse transcription-quantitative polymerase chain reaction (RT-qPCR) analyses of Nrf2 and NQO1. At the indicated time points $(3,6,12$ and $24 \mathrm{~h})$, total RNA was extracted using RNAiso Plus (Takara Biotechnology Co., Ltd., Dalian, China). The concentration of $2 \mu \mathrm{l}$ RNA was calculated $\left(\mu \mathrm{g} / \mathrm{ml}=\mathrm{OD}_{260} \mathrm{X}\right.$ $40 \mathrm{x}$ dilution factor), whereas the integrity of $5 \mu \mathrm{l}$ of RNA was visualized under ultraviolet light as two bands at $28 \mathrm{~S}$ and $18 \mathrm{~S}$ following $1.5 \%$ agarose gel electrophoresis. The total RNA was then reverse transcribed to cDNA by Prime Script ${ }^{\mathrm{TM}}$ RT reagent kit (Takara Bio, Inc., Otsu Japan) according to the manufacturer's protocols. Then mRNA transcription levels of $\mathrm{Nrf} 2$ and $\mathrm{NQOI}$ were assessed by Mx3000P qPCR System (Stratagene; Agilent Technologies, Inc., Santa Clara, CA, USA) with the SYBR R Premix Ex Taq ${ }^{\mathrm{TM}}$ (Tli RNaseH Plus) kit (Takara Bio, Inc.) and genes specific primers (Nrf2: Forward, 5'-GACGGTATGCAA CAGGACATTGAG-3' and reverse, 5'-AACTTCTGTCAG TTTGGCTTCTGGA-3'. NQO1: Forward, 5'-GGATTGGAC CGAGCTGGAA-3' and reverse, 5'-AATTGCAGTGAAGAT GAAGGCAAC-3'). GAPDH was used as an internal control (Forward, 5'-GCACCGTCAAGGCTGAGAAC-3' and reverse, 5'-TGGTGAAGACGCCAGTGGA-3'). qPCR was performed 
with the SYBR R Premix Ex Taq ${ }^{\mathrm{TM}}$ (Tli RNaseH Plus) kit with the following thermocycling conditions: $95^{\circ} \mathrm{C}$ for $30 \mathrm{sec}$ as initial denaturing followed by between 40 and 45 cycles of $95^{\circ} \mathrm{C}$ for $5 \mathrm{sec}$ and $55^{\circ} \mathrm{C}$ for $15 \mathrm{sec}$, and a final extension at $72^{\circ} \mathrm{C}$ for $10 \mathrm{sec}$. A melting curve analysis was automatically performed following amplification in qPCR instrument and MxPro qPCR software version 4.10 (cat no. MX3000P; Stratagene; Agilent Technologies, Inc.). The results of the expression of the target genes were quantified using the $2^{-\Delta \Delta \mathrm{Cq}}$ method (20).

Western blotting of Nrf2 and NQO1. BEAS-2B cells $\left(10^{6}\right.$ cells $\left./ \mathrm{ml}\right)$ were cultured overnight at $37^{\circ} \mathrm{C}$ and with $5 \%$ $\mathrm{CO}_{2}$, and then the RPMI-1640 medium was replaced with fresh medium containing the different concentrations of CTP $(1,2.5$, 5, 10, 20, 40 and $80 \mu \mathrm{g} / \mathrm{ml})$. The total cells were lysed with RIPA Lysis Buffer (CWBiotech, Beijing, China) at various time points (3, 6, 12 and $24 \mathrm{~h})$, and then the lysates were collected. These protein samples $(30 \mu \mathrm{g})$ were quantified using the standard curve method, resolved using SDS-PAGE (30\% polyacrylamide) and transferred to polyvinylidene difluoride membranes. The protein-bound membrane was blocked in TBS with Tween 20 buffer containing $10 \%$ milk for $2 \mathrm{~h}$ at room temperature, immunoblotted with a primary rabbit anti-human polyclonal antibody (1:500; Nrf2, cat no. ab62352; NQO1, cat no. ab34173; Abcam, Cambridge, UK) overnight at $4^{\circ} \mathrm{C}$, and then probed with a biotinylated secondary goat anti-rabbit antibody (1:1,000; cat no. ab205718; Abcam, Cambridge, UK). The immunoblots were visualized using a diaminobenzidine kit (Beijing Zhongqiao Jinqiao Biotechnology Co., Ltd., Beijing, China) according to the manufacturer's protocol and quantified using GeneSnap 7.2 Software (Syngene, Cambridge, UK). $\beta$-actin served as an internal control to verify that equal amounts of protein were loaded into each well of the SDS-PAGE gel (Rabbit anti-human polyclonal $\beta$-actin antibody, cat no. ab8227; Abcam, Cambridge, UK; $1: 1,000$ dilution in $20 \mathrm{mM}$ TBS buffer containing $10 \%$ milk and $0.1 \%$ Tween 20 ).

Statistical analysis. The data are presented as mean \pm standard deviation. The difference between groups for Nrf2 expression level was analyzed via one-way analysis of variance (ANOVA) and Student-Newman-Keuls post-hoc test, using Nrf2-NC group as control (Table II). The difference for colony formation was also tested by one-way ANOVA and Student-Newman-Keuls post-hoc test (Table III). All of the statistical analysis was performed using SPSS software (version 21.0; IBM Corp., Armonk, NY, USA). P<0.05 was considered to indicate a statistically significant difference.

\section{Results}

Cytotoxic effect of CTP on cell viability. The regression of cell survival rate alongside the toxicity of CTP was calculated using Probit regression. This was evaluated using the regression equation: $\mathrm{Y}$ (cell survival)=-1.25+1.375 log (exposure dose).

The $\mathrm{IC}_{50}$ for the effect of CTP on the cell survival was $8.11 \mu \mathrm{g} / \mathrm{ml}$. The final concentration applied in the subsequent experiment was $30 \%$ of the $\mathrm{IC}_{50}$, or $1 \mu \mathrm{g} / \mathrm{ml}$.

Effect of RNA interference. The optimization results identified that the optimal concentration of G418 was $400 \mu \mathrm{g} / \mathrm{ml}$. When
Table I. Sequences designed for RNA interference to silence Nrf2 expression.

\begin{tabular}{lc} 
Item & \multicolumn{1}{c}{ Sequence } \\
\hline Nrf2 & GGTTGCCCACATTCCCAAATC \\
shNC & GTTCTCCGAACGTGTCACGT \\
shGAPDH & GTATGACAACAGCCTCAAG \\
\hline
\end{tabular}

shNC, short hairpin negative control; Nrf2, NF-E2-related factor 2.

Table II. Expression levels of Nrf2 in the test group and the controls.

\begin{tabular}{llcl}
\hline Group & Level of Nrf2 & $F$ & P-value \\
\hline shNC & $1.001 \pm 0.107$ & 149.399 & $<0.001$ \\
shGAPDH & $0.144 \pm 0.015^{\mathrm{b}}$ & & \\
Nrf2 & $0.150 \pm 0.009^{\mathrm{b}}$ & & \\
\hline
\end{tabular}

${ }^{\mathrm{a}}$ Data presented as mean \pm standard deviation, $\mathrm{n}=3$. ${ }^{\mathrm{b}} \mathrm{P}<0.001$ compared with the Nrf2-NC group. shNC, short hairpin negative control; Nrf2, NF-E2-related factor 2.

cells were cultured in medium containing $400 \mu \mathrm{g} / \mathrm{ml} \mathrm{G} 418$, no abnormal morphology was observed on the first day. By the 7 th day, the cell concentration was $<50 \%$ and the cells stopped growing by the 13th day.

The expression of GFP indicated satisfactory transfection efficiency (Fig. 1). The cells were cultured for $24 \mathrm{~h}$ following transfection and observed using a fluorescence microscope. The expression of GFP was observed in $>40 \%$ of the cells.

The expression of Nrf2 was compared between the test group and controls, and the results are presented in Table II. It was notable that the expression of Nrf2 in the interference group was decreased compared with that in the negative control (shNC; $\mathrm{P}<0.001)$. However, there was no significant difference indicated between the interference group and the positive control (shGAPDH). Therefore, these results suggested that the interference group would be suitable for further investigation.

Soft agar assay for colony formation and the tumor-bearing mouse model. In this assay, four groups were designed to investigate the malignant transformation of BEAS-2B cells exposed to CTP. In these groups, the cells were treated with CTP, CTP and RNA interference (marked as RNAi), B(a)P and DMSO, respectively. The results indicated that when the BEAS-2B cells were subcultured for 20 passages, there was a significant increase in colonies in the RNAi group compared with the CTP and B(a)P groups $(\mathrm{P}<0.001)$. Furthermore, there was no notable difference between the CTP and $\mathrm{B}(\mathrm{a}) \mathrm{P}$ groups $(\mathrm{P}>0.066)$. Additionally, in the 30th passage cells, the numbers of colonies in descending order were; RNAi, CTP, B(a)P and DMSO (Table III), and the differences between any two groups were statistically significant. Furthermore, the results of the tumor-bearing mouse model indicated that cells of the 30th passage treated with CTP were able to grow into tumors (Fig. 2). Therefore, these results 
Table III. Results of the soft agar assay for colony formation.

\begin{tabular}{|c|c|c|c|c|c|c|}
\hline Passage & Groups & Cells & Colonies $^{\mathrm{a}}$ & Ratio, $\%{ }^{a}$ & $F$ & P-value \\
\hline \multirow[t]{4}{*}{ 10th } & DMSO & $1 \times 10^{4}$ & $21.25 \pm 2.63$ & $2.13 \pm 0.26$ & 0.928 & 0.457 \\
\hline & $\mathrm{B}(\mathrm{a}) \mathrm{P}$ & $1 \times 10^{4}$ & $21.75 \pm 1.71$ & $2.18 \pm 0.17$ & & \\
\hline & СТP & $1 \times 10^{4}$ & $22.00 \pm 2.16$ & $2.20 \pm 0.22$ & & \\
\hline & RNAi & $1 \times 10^{4}$ & $23.50 \pm 1.29$ & $2.35 \pm 0.13$ & & \\
\hline \multirow[t]{4}{*}{ 20th } & DMSO & $1 \times 10^{4}$ & $21.75 \pm 2.22$ & $2.18 \pm 0.22$ & 794.790 & $<0.001$ \\
\hline & $\mathrm{B}(\mathrm{a}) \mathrm{P}$ & $1 \times 10^{4}$ & $92.75 \pm 3.30$ & $9.28 \pm 0.33^{b}$ & & \\
\hline & CTP & $1 \times 10^{4}$ & $97.25 \pm 1.71$ & $9.73 \pm 0.17^{b}$ & & \\
\hline & RNAi & $1 \times 10^{4}$ & $126.25 \pm 4.57$ & $12.63 \pm 0.46^{\mathrm{b}, \mathrm{c}, \mathrm{d}}$ & & \\
\hline \multirow[t]{4}{*}{ 30th } & DMSO & $1 \times 10^{4}$ & $30.25 \pm 2.75$ & $3.03 \pm 0.28$ & 783.068 & $<0.001$ \\
\hline & $\mathrm{B}(\mathrm{a}) \mathrm{P}$ & $1 \times 10^{4}$ & $182.50 \pm 9.75$ & $18.25 \pm 0.98^{\mathrm{b}, \mathrm{d}}$ & & \\
\hline & CTP & $1 \times 10^{4}$ & $211.75 \pm 6.40$ & $21.18 \pm 0.64^{b, c}$ & & \\
\hline & RNAi & $1 \times 10^{4}$ & $243.50 \pm 6.25$ & $24.35 \pm 0.63^{b, c, d}$ & & \\
\hline
\end{tabular}

${ }^{a}$ Data presented as mean \pm standard deviation, $n=3 .{ }^{b} \mathrm{P}<0.001$ compared with the DMSO group. ${ }^{\mathrm{c}} \mathrm{P}<0.001$ compared with the $\mathrm{B}(\mathrm{a}) \mathrm{P}$ group ${ }^{\mathrm{d}} \mathrm{P}<0.001$ compared with the CTP group. DMSO, dimethyl sulfoxide; CTP, coal tar pitch; RNAi, RNA interference; B(a)p, benzo(a)pyrene.
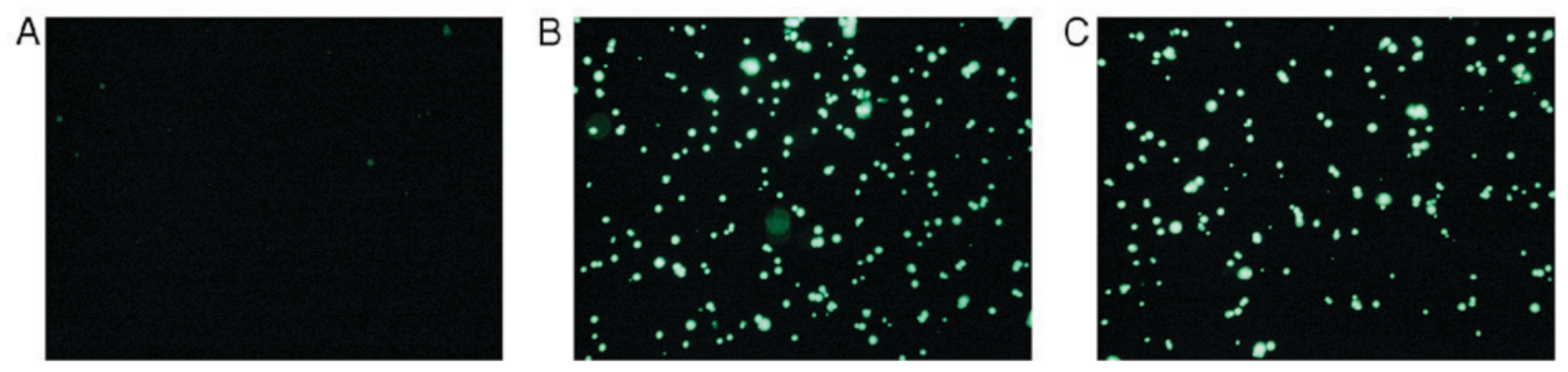

Figure 1. Cell morphology analyzed using fluorescence microscopy $24 \mathrm{~h}$ following transfection. (A) Negative control. (B) Positive control. (C) RNA interference for Nrf2. Nrf2, NF-E2-related factor 2.

suggested that CTP was able to induce considerable toxicity to BEAS-2B cells, which may lead to malignant transformation, and Nrf2 served a key function in this process.

Expression of Nrf2 and NQO1 was determined by RT-qPCR and western blot analysis. The expression of Nrf2 and NQO1 was determined at the mRNA level using RT-qPCR and at the protein level using western blotting. The results of the qPCR are presented in Fig. 3. These data revealed that there was a notable positive linear correlation between the expression of NQO1 and Nrf2 at the mRNA and protein levels in CTP and $\mathrm{B}(\mathrm{a}) \mathrm{P}$ groups (Table IV). The expression of Nrf2 at the mRNA and protein levels remained at a low level in the RNAi group whereas the levels were markedly increased in the CTP and $\mathrm{B}(\mathrm{a}) \mathrm{P}$ groups. However, the expression of NQO1 in the RNAi group decreased when the expression of Nrf2 was silenced. Thus, it was notable that the anti-oxidative system was triggered in BEAS-2B cells exposed to CTP and that Nrf2 was a required factor for the expression of anti-oxidative genes.

CTP-inducible rapid expression of $N r f 2$. The instantaneous response of Nrf2 was investigated when BEAS-2B cells were cultured with CTP. The expression of Nrf2 was monitored at time points of $3,6,12$ and $24 \mathrm{~h}$ following treatment with
Table IV. Results of the correlation analysis between the expression levels of NQO1 and Nrf2.

\begin{tabular}{llllll}
\hline & \multicolumn{2}{c}{ mRNA level } & & \multicolumn{2}{c}{ Protein level } \\
\cline { 2 - 3 } \cline { 5 - 6 } Analysis & $\mathrm{B}(\mathrm{a}) \mathrm{P}$ & $\mathrm{CTP}$ & & $\mathrm{B}(\mathrm{a}) \mathrm{P}$ & $\mathrm{CTP}$ \\
\hline $\begin{array}{l}\text { Correlation } \\
\text { coefficient }\end{array}$ & 0.9757 & 0.9987 & & 0.9929 & 0.9667 \\
\cline { 5 - 6 } & & & & &
\end{tabular}

The mRNA or protein level of Nrf2 in 10, 20 and 30th passage of normal BEAS-2B cells treated with $\mathrm{B}(\mathrm{a}) \mathrm{P}$ and $\mathrm{CTP}$ was plotted on the abscissa and that of NQO1 on the ordinate. Then, the linearity was fitted, and the correlation coefficient was calculated. Nrf2, NF-E2-related factor 2; NQO1, NAD(P)H:quinone oxidoreductase 1; CTP, coal tar pitch; B(a)p, benzo(a)pyrene.

CTP (Fig. 4). The results revealed that the expression of Nrf2 increased at the mRNA and protein levels once the cells were treated with CTP. The expression reached maximal values at $6 \mathrm{~h}$ and then returned to the basal level by $12 \mathrm{~h}$. This indicated that $\mathrm{Nrf} 2$ was a rapid response factor that was sensitive to CTP exposure. 
A
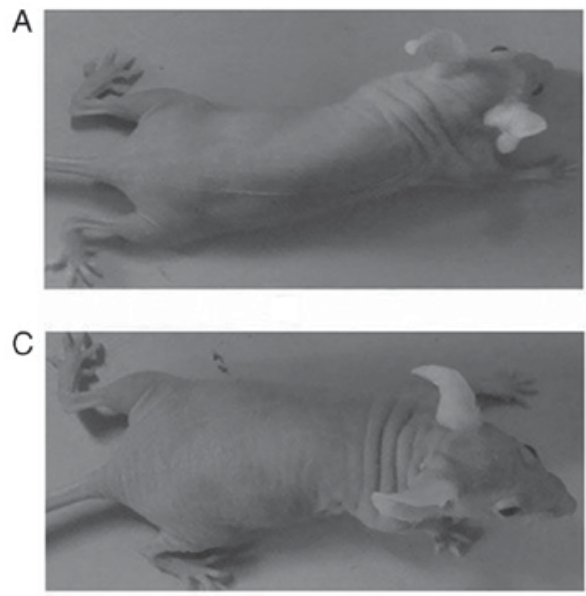
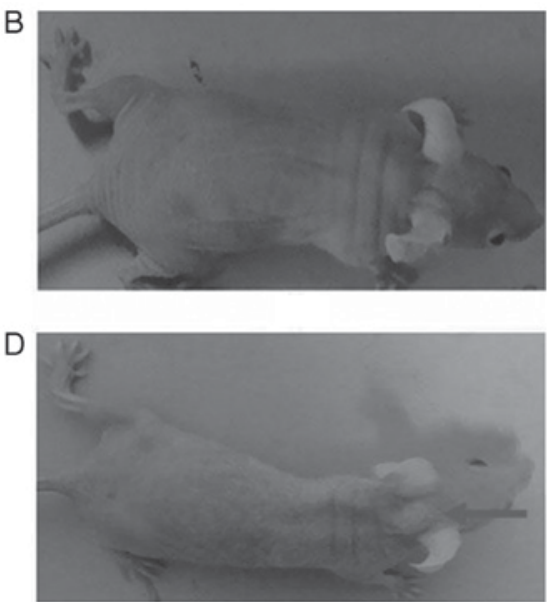

Figure 2. Results of the tumor-bearing mouse model. (A) Normal BEAS-2B cells. (B) BEAS-2B cells of the vehicle dimethyl sulfoxide control group. (C) Cells treated with CTP, 20th passage. (D) Cells treated with CTP, 30th passage. Tumor indicated with an arrow. CTP, coal tar pitch.

A

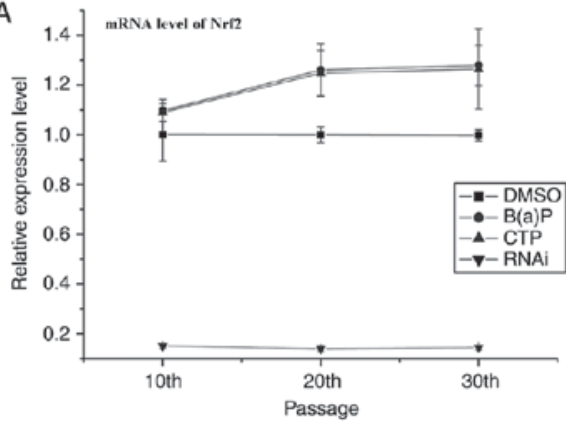

C

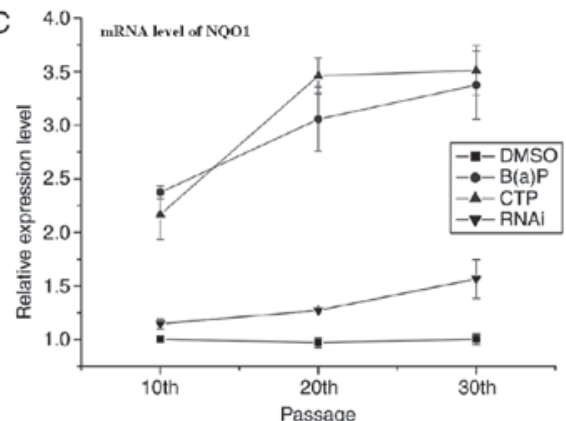

B

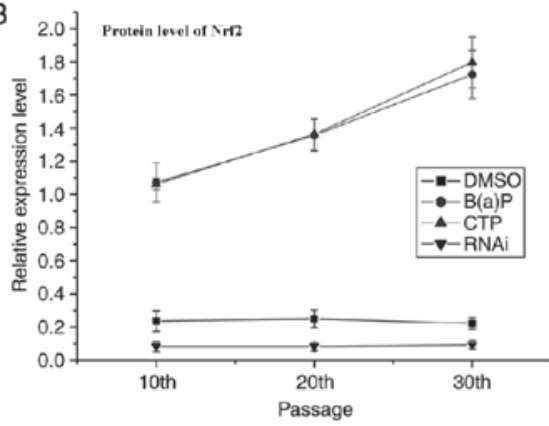

D 3.2. Protein level of $\mathrm{NQO1}$

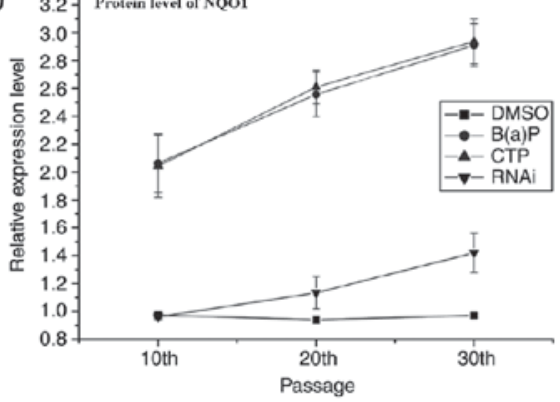

Figure 3. Expression levels of Nrf2 and NQO1 in BEAS-2B cells during subculture. (A) The mRNA level of Nrf2. (B) The protein level of Nrf2. (C) The mRNA level of NQO1. (D) The protein level of NQO1. Nrf2, NF-E2-related factor 2; NQO1, NAD(P)H:quinone oxidoreductase 1; DMSO, dimethyl sulfoxide; CTP, coal tar pitch; RNAi, RNA interference; B(a)p, benzo(a)pyrene.

\section{Discussion}

The results of the soft agar assay for colony formation demonstrated that malignant transformation occurred in cells at the 20th passage, and a greater degree of transformation was observed in cells at the 30th passage. Therefore, CTP may have the potential to induce malignant transformation in BEAS-2B cells. The expression level of Nrf2 and NQO1 increased at the mRNA and protein levels during the extended culture procedure. Thus, the anti-oxidative system may take part in the malignant transformation of BEAS-2B cells exposed by CTP.

It has been reported that Kelch-like ECH-associated protein 1 retains Nrf2 in the cytoplasm and targets it to the ubiquitin-proteasome degradation signaling pathway under

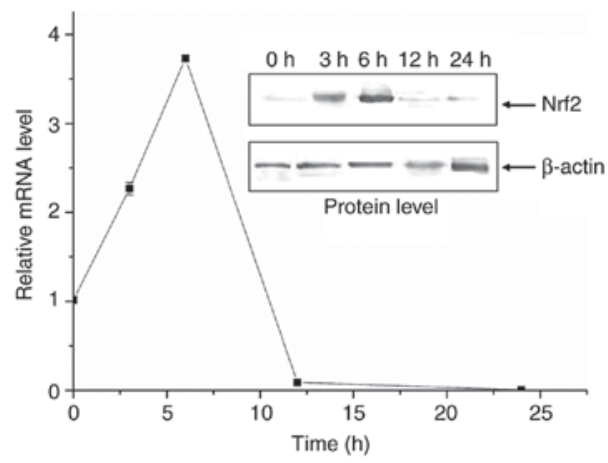

Figure 4. Time course of the CTP-induced level of Nrf2. BEAS-2B cells were treated with CTP at $3 \mu \mathrm{g} / \mathrm{ml}$ and harvested at five time points $(0,3,6,12$ and $24 \mathrm{~h}$ ), as indicated. $\beta$-actin served as an internal control. CTP, coal ta pitch; Nrf2, NF-E2-related factor 2. 
normal homeostatic conditions. Upon oxidative stress, Nrf2 translocates to the nucleus and heterodimerizes with a small Maf protein, allowing the complex to bind to ARE and activate the expression of NQO1 for protection against oxidative stress (11).

$\mathrm{Nrf2}$ is a required factor for the expression of NQO1. Thus, the expression of NQO1 is dependent on the level of Nrf2 (21). This was observed in the CTP and $\mathrm{B}(\mathrm{a}) \mathrm{P}$ groups in the present study. The level of NQO1 increased in parallel with increases in the level of Nrf2. There was a notable positive correlation between the expression of NQO1 and Nrf2 in the normal cells exposed to CTP. When the expression of Nrf2 was blocked, the expression of NQO1 decreased accordingly. Thus, it is hypothesized that CTP is able to trigger the Nrf2-regulated anti-oxidative system during malignant transformation.

Gas chromatography-mass spectrometry analysis was combined with the NIST library (https://www.nist.gov) to identify the chemical composition of the CTP extracts, and the relative content of each component was determined by a normalized method (22). The compounds of the CTP extracts are divided into four categories according to their benzene ring structure: i) Polycyclic aromatic hydrocarbons (PAHs); ii) heterocyclic hydrocarbons; iii) single-ring aromatic hydrocarbons; and iv) cycloaliphatic hydrocarbons. These four components account for $90.981,7.745,1.058$ and $0.216 \%$ of the extracts, respectively. This suggested that the PAHs may be the main trigger of the signaling pathway regulated by Nrf2.

It has been reported that oxidative damage caused by PAHs may be one factor that leads to cancer (23). PAHs may be metabolized to reactive metabolites, which may produce DNA adducts that result in DNA mutations, altered gene expression profiles and tumors. In the present study, the results of a tumor-bearing mouse model indicated that the cells treated with CTP for between 20 and 30 passages were able to grow into tumors.

These data suggest that Nrf2 may be a factor associated with the development of lung cancer induced by CTP. Therefore, Nrf2 may be a potential intervention target for prevention of CTP-induced lung cancer.

In conclusion, extended culture with CTP was able to induce malignant transformation of BEAS-2B cells. The anti-oxidative signaling pathway was activated in the BEAS-2B cells exposed to CTP. Nrf2 is a factor that responded rapidly to the exposure of CTP, regulating the downstream expression of phase II detoxification enzyme NQO1 to relieve cell damage. This action continued throughout the extended exposure process. In addition, the malignant transformation process was accelerated when Nrf2 expression was inhibited. These results indicated that $\mathrm{Nrf2}$ may be a factor associated with the development of CTP-induced lung cancer.

\section{Acknowledgements}

The present study was supported by the National Natural Science Foundation of China (grant nos. 81573203, 81402721 and 81402712).

\section{Competing interests}

The authors declare that they have no competing interests.

\section{References}

1. Gibbs GW and Labrèche F: Cancer risks in aluminum reduction plant workers: A review. J Occup Environ Med 56 (5 Suppl): S40-S59, 2014

2. Kim SY, Lee J, Kim BH, Kim YJ, Yang KS and Park MS: Facile synthesis of carbon-coated silicon/graphite spherical composites for high-performance lithium-ion batteries. ACS Appl Mater Interfaces 8: 12109-12117, 2016.

3. Yamaoka M, Asami SS, Funaki N, Kimura S, Yingjie L, Fukuda T and Yamashita M: Preparation of organic light-emitting diode using coal tar pitch, a low-cost material, for printable devices. PLoS One 8: e62903, 2013.

4. Koganti A, Singh R, Rozett K, Modi N, Goldstein LS, Roy TA, Zhang FJ, Harvey RG and Weyand EH: 7H-benzo[c]fluorene: A major DNA adduct-forming component of coal tar. Carcinogenesis 21: 1601-1609, 2000.

5. Lavoué J, Gérin M, Côté J and Lapointe R: Mortality and cancer experience of Quebec aluminum reduction plant workers. Part I: The reduction plants and coal tar pitch volatile (CTPV) exposure assessment. J Occup Environ Med 49: 997-1008, 2007.

6. Spinelli JJ, Demers PA, Le ND, Friesen MD, Lorenzi MF, Fang R and Gallagher RP: Cancer risk in aluminum reduction plant workers (Canada). Cancer Causes Control 17: 939-948, 2006.

7. Bolliet $C$, Juery $C$ and Thiebaut B: Impact of oxidation process on polycyclic aromatic hydrocarbon (PAH) content in bitumen. J Occup Environ Hyg 10: 435-445, 2013.

8. Feng F, Wu Y, Zhang S, Liu Y, Qin L, Wu Y, Yan Z and Wu W: Macrophages facilitate coal tar pitch extract-induced tumorigenic transformation of human bronchial epithelial cells mediated by NF-kB. PLoS One 7: e51690, 2012.

9. Valko M, Leibfritz D, Moncol J, Cronin MT, Mazur M and Telser J: Free radicals and antioxidants in normal physiological functions and human disease. Int J Biochem Cell Biol 39: 44-84, 2007.

10. Pilger A and Rudiger HW: 8-Hydroxy-2'-deoxyguanosine as a marker of oxidative DNA damage related to occupational and environmental exposures. Int Arch Occup Environ Health 80: 1-15, 2006.

11. Taguchi K, Motohashi $\mathrm{H}$ and Yamamoto M: Molecular mechanisms of the Keap1-Nrf2 pathway in stress response and cancer evolution. Genes Cells 16: 123-140, 2011.

12. Biswas C,Shah N, Muthu M,La P,Fernando AP, Sengupta S, Yang G and Dennery PA: Nuclear heme oxygenase-1 (HO-1) modulates subcellular distribution and activation of Nrf2, impacting metabolic and anti-oxidant defenses. J Biol Chem 289: 26882-26894, 2014.

13. Ma Q: Role of nrf2 in oxidative stress and toxicity. Annu Rev Pharmacol Toxicol 53: 401-426, 2013.

14. Li LR, Dong H, Song E, Xu X, Liu L and Song Y: Nrf2/ARE pathway activation, $\mathrm{HO}-1$ and $\mathrm{NQ} 01$ induction by polychlorinated biphenyl quinone is associated with reactive oxygen species and PI3K/AKT signaling. Chem Biol Interact 209: 56-67, 2014.

15. Anwar-Mohamed A, Elshenawy OH, Soshilov AA, Denison MS, Chris Le X, Klotz LO and El-Kadi AO: Methylated pentavalent arsenic metabolites are bifunctional inducers, as they induce cytochrome P450 1A1 and NAD(P)H:quinone oxidoreductase through AhR- and Nrf2-dependent mechanisms. Free Radic Biol Med 67: 171-187, 2014.

16. Nioi P and Hayes JD: Contribution of NAD(P)H:quinone oxidoreductase 1 to protection against carcinogenesis, and regulation of its gene by the Nrf2 basic-region leucine zipper and the arylhydrocarbon receptor basic helix-loop-helix transcription factors. Mutat Res 555: 149-171, 2004.

17. Oh ET and Park HJ: Implications of NQO1 in cancer therapy. BMB Rep 48: 609-617, 2015.

18. National Center for Biotechnology Information, https://www. ncbi.nlm.nih.gov. Accessed January, 2018

19. Feed ingredients for laboratory animal, National standard in China, GB 14924.3, 2010.

20. Livak KJ and Schmittgen TD: Analysis of relative gene expression data using real-time quantitative PCR and the 2(T)(-Delta Delta C) method. Methods 25: 402-408, 2001.

21. Yu R, Chen C, Mo YY, Hebbar V, Owuor ED, Tan TH and Kong AN: Activation of mitogen-activated protein kinase pathways induces antioxidant response element-mediated gene expression via a Nrf2-dependent mechanism. J Biol Chem 275: 39907-39913, 2000.

22. Feng FF, Qin LJ, Wu YJ, Li YQ and Wu YM: GC-MS analysis of coal tar pitch fume exract. Ind Health Occup Dis 37: 198-203, 2011 (In Chinese).

23. Moorthy B, Chu C and Carlin DJ: Polycyclic aromatic hydrocarbons: From metabolism to lung cancer. Toxicol Sci 145: 5-15, 2015. 